\title{
FORMULATION AND EVALUATION OF TRAZODONE HYDROCHLORIDE ORODISPERSIBLE TABLETS
}

\author{
AKILADEVI D*, HARI PRAKASH K, BIJU GB, MADHUMITHA N \\ Department of Pharmaceutics, School of Pharmaceutical Sciences, Vels Institute of Science, Technology and Advanced Studies (VISTAS), \\ Chennai, Tamil Nadu, India. Email akilaajcp@gmail.com
}

Received: 10 October 2018, Revised and Accepted: 11 December 2018

\section{ABSTRACT}

Objective: The objective of the existing research was to develop an oral disintegrating dissolving system as one of the taste masking orodispersible forms together of trazodone hydrochloride tablets using direct compression technique through the use of superdisintegrants together with FlowLac, StarLac, and sodium starch glycolate.

Methods: The tablets were formulated using the direct compression approach. The drugs prepared have been evaluated for diverse parameters which include hardness, friability, weight variation, drug content uniformity, water absorption ratio, in vitro drug release, and wetting time.

Results: The hardness of all formulations from F1 to F7 proved that the tablet means thickness was nearly uniform in all formulations with the range of $0.520 \mathrm{~mm}-0.522 \mathrm{~mm}$. Water absorption of prepared formulations was found to be $68.59 \%-73.21 \%$. Bulk density, tapped density, and friability of the formulations were established within the limits, results of in vitro drug release study showed the drug released between $90.27 \%$ and $96.17 \%$ at $60 \mathrm{~min}$.

Conclusion: The overall study concluded that orodispersible tablets of trazodone hydrochloride have greater dissolution rate and will result in enhanced bioavailability. The taste masked systems are designed to provide better acceptability, improved bioavailability, for chronic patients. The study results revealed that the formulation F6 was contemplated as the top formulation.

Keywords: FlowLac, Orodispersible, StarLac, Trazodone hydrochloride.

(C) 2018 The Authors. Published by Innovare Academic Sciences Pvt Ltd. This is an open access article under the CC BY license (http://creativecommons. org/licenses/by/4. 0/) DOI: http://dx.doi.org/10.22159/ajpcr.2018.v11s4.31740

\section{INTRODUCTION TO ORAL DISPERSIBLE TABLETS}

Over the past few decades, the oral drug shipping has been acknowledged due to the most widely applied course of management. The tablets are described as strong pharmaceutical dosage form containing drug substances with no or with additives, structured through compression, or molding strategies. Since part of the $19^{\text {th }}$ century, it is used widely [1]. The techniques to formulate the capsules are direct compression, dry granulation, and moist granulation [2]. At present, the demand of the development of orally disintegrating tablets (ODTs) is in demand because it has a full-size effect on the patient compliance. Those people who have swallowing difficulties can go oral disintegrating tablets. Dysphagia [3] is commonplace among all age companies and extra unique with pediatric, geriatric population for patients with nausea, vomiting, and motion sickness headaches [4]. A wide range of population accepts bitter pills as ODT's due to its good taste and taste growth. Orally disintegrating drugs are also known as disintegrating drugs, mouth dissolving tablets, quick disintegrating pills, orodispersible pills, rapid porous pills, speedy dissolving capsules, and fast melts. They disperse readily in the mouth within 3 min before swallowing [5].

The special benefits of ODT's are as follows: (i) ODTs are unit strong dosage forms that offer right balance, correct dosing, clean production, and small packaging length, and in addition to these points, patient handles it easily [6-9]. (ii) They may be smooth to manage for geriatric and pediatric patient as well as hospitalized sufferers (specifically for psychiatric patient and mentally retarded sufferers). (iii) The fast disintegration of tablet accounts for quick dissolution and the speedy onset of movement [10]. The bioavailability of medicine which is absorbed from mouth, pharynx, and esophagus is enhanced [11-13].
The hepatic metabolism is avoided due to pregastric absorption of medicine, and thereby, it decreases the dose and enhances the bioavailability [14].

Various strategies employed in the formulation of ODT's encompass.

\section{Lyophilization or freeze-drying}

With the help of shape-forming additives, the solvent is removed from a frozen suspension or solution of the active pharmaceutical ingredient by a process called lyophilization. A glossy appearance of amorphous structure results in particularly porous and light-weight product when a drug is subjected to freeze-drying along with the additives. The ensuing tablet has dissolved right away to launch the drug, but the ODT's fashioned through lyophilization has got low mechanical electricity, terrible stability at an elevated temperature, and humidity [15] and particularly freeze drier is luxurious.

\section{Molding}

Molding consists of moistening, dispersing, or dissolving the drug with a solvent and the prepared wet combination molded into tablets. Since the molded tablets have low mechanical energy, it leads to erosion and breakage during handling [16].

\section{Cotton candy manner [17]}

The development of a matrix of polysaccharides with the aid of the simultaneous act of flash melting and spinning was carried out with the cotton sweet technique. The candy matrix is then grinded and mixed with lively substances and finally compressed to ODT. Accommodation of high doses of the drug as well as high mechanical strength is achieved by this process. The use of high temperature is the limitation of this technique. 


\section{Spray drying}

The exceedingly, porous, high-quality powders are acquired by this method. The disintegration and dissolution were similarly stepped forward with the aid of adding effervescent agents which include citric acid, tartaric acid, and sodium bicarbonate. To get a porous powder, the formulation is subjected to spray drying. The ODT obtained from this approach is disintegrated much $<20 \mathrm{~s}$.

\section{Mass extrusion}

It is a novel technique used in application of polymer processing technology to prepare pharmaceutical dosage forms. This technique involves softening blend using the polymeric solvent along with cosolvent. Then, the expulsion of softened mass is done through the extruder or syringe to get a cylinder of the product [18]

\section{Compaction}

The ODTs are prepared using incorporating a hydrophilic waxy binder (notable polystrate) inside the method through soften granulation approach.

\section{Phase transition process}

The tablets were produced with the aid of compressing a powder mixture in which a two-component single-phase liquid is cooled and transforms into two solid phases. The tablet hardness turned into accelerated after the heating manner, due to the growth of interparticle bonds or the bonding floor region in capsules brought on through phase transition of lower melting factors.

\section{Sublimation}

The key factor which is responsible for the rapid disintegration of ODT is the existence of an extremely porous shape in the tablet. However, the conventional capsules contain incredibly water-soluble substances, they frequently fail to fall apart swiftly due to low porosity.

\section{Three-dimensional printing (3DP)}

It is a unique speedy dissolving drug delivery tool (DDD) with free powders in it was fabricated the usage of the 3DP procedure. By depending on computer-aided layout fashions, DDD containing the drug acetaminophen was organized robotically through 3DP machine [19]. Tablet undergoes fast disintegration due to the fast water penetration into the tablet as a consequence of the huge pore length and large average pore volume.

\section{Conventional methods}

The traditional methods in formulating ODT's together with direct compression, dry granulation [20], and wet granulation methods using superdisintegrants had been adapted to provide ODT's.

This present research presents the rationale behind the development of an oral fast disintegrating dissolving system is that the tablet disintegrates in the mouth in a fraction of minute, rapidly releases the drug in the stomach following oral administration. The significance of ODT's is especially delivering bitter drug with ease and rapid release, thereby improving safety and reducing toxicity.

Trazodone is regarded as a psychoactive compound with sedative, anxiolytic, and antidepressant drug which is likewise described as having less usefulness inside the remedy of the acute phase of cerebral stroke. Trazodone acts as a serotonin- 2 receptor antagonist, due to this antagonistic activity, it decreases extracellular gammaamino-butyric acid levels within the cerebral cortex, by blocking of 5-hydroxytryptamine $2 \mathrm{~A}$ receptors [21].

After oral administration, the plasma level concentration of trazodone hydrochloride is $2 \mathrm{~h}$ after single dosing when taken with food. The bioavailability of trazodone hydrochloride is $65 \%$ and its biological half-life is 5-9 h. The purpose of the prevailing investigation was to develop an orodispersible tablet of trazodone hydrochloride through direct compression approach to mask the noxious taste of trazodone hydrochloride.

\section{METHODS}

Trazodone hydrochloride was gifted by Aurobindo Pharma Pvt., Ltd., lactose (Pharmatose DCL-11) and Aerosil were gifted by M.B Chemicals, microcrystalline cellulose (Avicel PH 200) was procured from Simcon Laboratories Pvt., Ltd., sodium starch glycolate and pregelatinized starch from Kanwarlal Laboratories, FlowLac and StarLac from Meggle Pharma, and magnesium stearate was gifted from Cabot Sanmar Limited.

\section{Development of standard calibration curve}

Serial concentrations of trazodone hydrochloride in $0.1 \mathrm{~N}$ hydrochloride buffer (pH 1.2) having concentrations between 0 and $70 \mathrm{mcg} / \mathrm{ml}$ were prepared. The absorbance of the prepared solutions was measured spectrophotometrically at $\lambda_{\max } 278 \mathrm{~nm}$. The absorbance was plotted against the concentration and regression lines were calculated which was tabulated in Table 1 and illustrated in Fig. 1.

\section{Preformulation studies}

Organoleptic properties

Color

With the aid of butter paper, a small quantity of trazodone hydrochloride was taken and viewed in a well-illuminated place.

Taste and odor

A very less amount of trazodone hydrochloride was used to examine the taste with the help of tongue and also to determine the smell.

Formulation of an orodispersible tablet of trazodone hydrochloride Trazodone hydrochloride was prepared by direct compression method. A small quantity of trazodone hydrochloride was taken in a butter paper and considered in a well-illuminated place. A very much less amount of the trazodone hydrochloride was used to get the flavor with the help of the tongue as well as odor to get the smell. The drug along with polymer and other ingredient is mixed in weight proportion. Every ingredient (except granular directly compressible excipients) was passed through \# 60-mesh individually. Followed by lubricating, the powder blends with the help of magnesium stearate $(1 \% \mathrm{wt} / \mathrm{wt})$ which was further subjected to compression into a $600 \mathrm{mg}$ tablet with the help of flat-face spherical tooling on a single punch tablet machine (Table 2).

Table 1: Calibration values of trazodone hydrochloride in $0.1 \mathrm{~N}$ hydrochloric acid

\begin{tabular}{lll}
\hline S. No. & $\begin{array}{l}\text { The concentration of drug } \\
\text { sample }\end{array}$ & $\begin{array}{l}\text { The absorbance of the drug } \\
\text { sample }\end{array}$ \\
\hline 1. & 10 & 0.065 \\
2. & 20 & 0.130 \\
3. & 30 & 0.194 \\
4. & 40 & 0.259 \\
5. & 50 & 0.326 \\
6. & 60 & 0.388 \\
7. & 70 & 0453 \\
\hline
\end{tabular}

Table 2: Formulation of ODT

\begin{tabular}{lllllllll}
\hline S. No & Ingredients & F1 & F2 & F3 & F4 & F5 & F6 & F7 \\
\hline 1. & Trazodone hydrochloride & 150 & 150 & 150 & 150 & 150 & 150 & 150 \\
2. & Lactose & 300 & - & - & - & - & - & - \\
3. & FlowLac & - & 176 & 352 & 402 & - & - & 300 \\
4. & StarLac & - & 176 & - & - & 432 & 432 & - \\
5. & Microcrystalline cellulose & 102 & 50 & 50 & - & 80 & - & 102 \\
6. & Sodium starch glycolate & 30 & 30 & 30 & 30 & - & 12 & 30 \\
7. & Aerosil & 12 & 12 & 12 & 12 & 12 & - & 12 \\
8. & Magnesium stearate & 6 & 6 & 6 & 6 & 6 & 6 & 6 \\
Total weight in (mg) & 600 & 600 & 600 & 600 & 600 & 600 & 600 \\
\hline
\end{tabular}

ODT: Orally disintegrating tablet 


\section{Evaluation of orodispersible tablets of trazodone hydrochloride}

\section{Evaluation parameters of pre-compressed powder}

Fixed funnel method was used to determine the angle of repose. The funnel possessing $10 \mathrm{~mm}$ of an interior diameter of the stem was set at a height of $2 \mathrm{~cm}$ above the stage. The powder sample $(10 \mathrm{~g})$ was taken and gradually passed through the funnel to form a pile which touches the stem of the funnel. Around the pile base, a rough circle was drawn and radius of the formed pile was measured.

The angle of repose was determined by means of the following equation.

$$
\theta=\tan ^{-1}(\mathrm{~h} / \mathrm{r})
$$

Where,

$\theta=$ angle of repose

$\mathrm{h}=$ height of the pile and

$r=$ radius of powder cone.

\section{Bulk density}

About $20 \mathrm{~g}$ of the sample was poured into a $100 \mathrm{ml}$ graduated cylinder with the help of a funnel to find out the bulk densities of the granules. The volume in the cylinder which was occupied by the granules was measured and the bulk density was calculated according to the formula.

$$
\text { Bulk density }(\mathrm{g} / \mathrm{ml})=\text { Weight of the sample }(\mathrm{g}) / \text { volume }
$$
which is occupied by the sample.

\section{Tapped density}

About $25 \mathrm{~g}$ of the sample was poured into the $100 \mathrm{ml}$ graduated cylinder with the help of a funnel to find out the tapped densities of the granules. From the height of 2 inches, the cylinder was tapped continuously for getting a constant volume. After measuring the constant volume in the cylinder, tapped density was calculated according to the given formula.

$$
\text { Tapped density }(\mathrm{g} / \mathrm{ml})=\quad \begin{gathered}
\text { Weight of sample }(\mathrm{g}) / \text { volume } \\
\text { occupied by the sample }
\end{gathered}
$$

\section{Carr's index}

Carr's index was analyzed using the following formula:

$$
\text { Carr's index }=(\text { tapped density-bulk density }) / \text { tapped density }) / 100
$$

\section{Hausner's ratio}

The below formula was used for calculating the Hausner's ratio of the granules:

- Hausner's ratio = Tapped density $/$ bulk density

Following are the specification for the Hausner ratios:

- Hausner ratios $<1.25$ indicate better flow properties

- Hausner ratios $>1.25$ indicate poor flow properties

\section{Weight variation}

From the formulated tablets, randomly 20 tablets were chosen and the average weight was estimated; then, it was evaluated with the individual weight of the tablet.

$\%$ deviation $=$ Tablet weight-average weight $/$ tablet weight $\times 100$

\section{Friability}

Roche friabilator was employed to check the friability of the tablet. The friabilator was operated at 100 revolutions after placing the preweighed samples of tablets. The tablets were deducted and then again weighed.

$\mathrm{F}=\mathrm{W} 0-\mathrm{W} / \mathrm{W} \times 100$
Where, $\mathrm{W} 0=$ Initial weight and $\mathrm{W}=$ Final weight.

\section{Thickness}

Vernier caliper was used to determine the thickness of the tablet. From every formulation, the thickness of five tablets was established.

\section{Hardness}

Tablet hardness testing is the laboratory test used to measure the strength of the tablet which also depends on the shape of the tablet. A fairly handy instrument, Monsanto hardness tester was used to determine the hardness of the tablet. Six tablets were determined for formulation F1-F7.

\section{Disintegration time}

Using digital disintegration apparatus, the disintegration time of six tablets from every formulation was analyzed. The temperature maintained in the disintegration apparatus was $37 \pm 2^{\circ} \mathrm{C}$ and $900 \mathrm{ml}$ distilled water was used to maintain the volume. In each tube, six tablets were introduced; then, the disc was placed and basket rack was placed in a 1-L beaker containing water $37 \pm 2^{\circ}{ }^{\circ} \mathrm{C}$ and the apparatus was operated for $3 \mathrm{~min}$ and the disintegration time in terms of seconds was noted.

\section{Wetting time}

The small Petri dish containing simulated saliva $\mathrm{pH}$ (volume $-6 \mathrm{ml}$ ) was taken and a cut of tissue paper $(12 \times 10.75)$ was folded twice and kept on it (Petri dish); further, the prepared formulation was positioned on the paper. Total time required for the entire wetting of the tablet was noted. The study was performed in triplicate.

\section{The uniform of dispersion test}

Two tablets from each batch were separately kept in water $(100 \mathrm{ml})$, and for $2 \mathrm{~min}$, it was gently stirred. The depression was passed through 22 meshes. If there is no residue on the screen, then the tablet passes the test.

\section{Water absorption ratio}

Water absorption ratio was determined to identify the capability of disintegrants to swell in the existence of water. The weight of the tablet after as well as before the test was determined. Using the formula, the water absorption ratio $(\mathrm{R})$ was worked out.

$$
\mathrm{R}=\mathrm{Wb}-\mathrm{Wa} / \mathrm{Wa} \times 100
$$

Where,

$\mathrm{Wb}=$ Weight of the tablets after water absorption test. $\mathrm{Wa}=$ Weight of the tablets before water absorption test.

\section{Dissolution studies}

With the help of USP type II apparatus, dissolution studies were carried out at $50 \mathrm{rpm}$. The dissolution media used for this study was $0.1 \mathrm{~N}$ hydrochloric acid. The temperature was retained at $37 \pm 2^{\circ} \mathrm{C}$. At specific time interval, aliquots of dissolution media were withdrawn and filtered. Moreover, it was restored with the same amount of fresh dissolution media. Further, the filtered solution was observed spectrometrically at $286 \mathrm{~nm}$ to find out the drug content. For all designed formulations, the dissolution study was carried and the results were compared with conventional and marketed tablet Apotex.

\section{RESULTS}

\section{Preformulation studies}

The data obtained for pre-compression parameters are given in Table 3. The values for angle of repose of every formulation (F1-F7) ranged from $24^{\circ \circ} 30^{\prime}$ to $35^{\circ} 28^{\prime}$ which indicated the good flow property of the powder blend. The compressibility index and Hausner's ratio were 
Table 3: Evaluation of pre-compression parameters of a powder blend

\begin{tabular}{|c|c|c|c|c|c|c|c|c|}
\hline S. no & Parameters & F1 & F2 & F3 & F4 & F5 & F6 & F7 \\
\hline 1. & Bulk density (g/ml) & 0.472 & 0.541 & 0.524 & 0.451 & 0.428 & 0.469 & 0.578 \\
\hline 2. & Tapped density $(\mathrm{g} / \mathrm{ml})$ & 0.749 & 0.823 & 0.814 & 0.717 & 0.568 & 0.526 & 0.636 \\
\hline 3. & Hausner's ratio & 1.585 & 1.48 & 1.55 & 1.58 & 1.12 & 1.17 & 1.18 \\
\hline 4. & Compressibility index (\%) & 36.91 & 32.58 & 35.63 & 37.02 & 29.23 & 31.21 & 30.76 \\
\hline 5. & Angle of repose & $27^{\circ} 76^{\prime}$ & $29^{\circ} 68^{\prime}$ & $24^{\circ} 65^{\prime}$ & $26^{\circ} 65^{\prime}$ & $24^{\circ} 54^{\prime}$ & $26^{\circ} 46^{\prime}$ & $26^{\circ} 85^{\prime}$ \\
\hline
\end{tabular}

Table 4: Weight variation test for F1-F7 formulations

\begin{tabular}{llll}
\hline Batch no & $\begin{array}{l}\text { Tablet } \\
\text { weight }(\mathbf{X}) \mathbf{~ m g}\end{array}$ & $\begin{array}{l}\text { Average tablet } \\
\text { weight }\left(\mathbf{X}_{\mathbf{1}}\right) \mathbf{~ m g}\end{array}$ & \% deviation \\
\hline F1 & $598-601$ & 599.65 & $(-) 0.665-0.537$ \\
F2 & $599-603$ & 300.45 & $(-) 0.582-1.007$ \\
F3 & $596-604$ & 600.15 & $(-) 0.168-1.515$ \\
F4 & $597-602$ & 599.75 & $(-) 1.113-0.892$ \\
F5 & $599-603$ & 600.4 & $(-) 0.562-1.027$ \\
F6 & $598-603$ & 600 & $(-) 0.806-1.185$ \\
F7 & $600-603$ & 600.8 & $(-) 0.32-0.869$ \\
\hline
\end{tabular}

Table 5: Post-compression parameters for trazodone hydrochloride orodispersible tablets

\begin{tabular}{llll}
\hline Batch no & Hardness $\left(\mathbf{k g} / \mathbf{c m}_{\mathbf{2}}\right)$ & Thickness (mm) & Friability (\%) \\
\hline F1 & 2.7 & 5.22 & 0.25 \\
F2 & 2.9 & 5.24 & 0.27 \\
F3 & 2.6 & 5.21 & 0.25 \\
F4 & 3.2 & 4.99 & 0.28 \\
F5 & 3.5 & 4.94 & 0.26 \\
F6 & 3.1 & 5.22 & 0.23 \\
F7 & 3.6 & 5.21 & 0.29 \\
\hline
\end{tabular}

found between $25-34.2 \%$ and $1.12-1.2$ representing that the powder blend possesses the characteristics for direct compression. Flow property of powder was examined before the compression and it is considered as an important parameter for the content uniformity.

\section{Evaluation of post-compression parameters}

Weight variation test

Mean weight of total 20 tablets was analyzed; then, it was evaluated with the individual weight of the tablet. According to IP, weight of the tablets should lie inside the I.P limits [21]. The results are tabulated in Table 4.

The other post-compression parameters for trazodone hydrochloride orodispersible tablets by direct compression method are shown in Tables 5 and 6 .

In vitro drug release studies of trazodone hydrochloride orodispersible tablets

The in vitro drug release study of formulations F1-F7 was conducted in $0.1 \mathrm{~N}$ hydrochloric acid with the $\mathrm{pH}$ of 1.2 for $60 \mathrm{~min}$ using paddle apparatus as shown in Table 7. It was observed that the cumulative percentage drug release from the F6 formulation was $96.17 \%$. For the innovated formulation, the cumulative percentage drug release was found to be $98.56 \%$. The promising formulation F6 was compared with the innovated product (Apotex $150 \mathrm{mg}$ IR tablets) for the in vitro drug release profile.

\section{DISCUSSION}

Bulk density and tapped density of the formulation were established within the limits, which was helpful in stating flow property of the powder. From the tabulated results (Table 5), it was proved that the tablet means thickness was nearly uniform in all formulations with the range of $0.520-0.522 \mathrm{~mm}$. As the amount of excipients

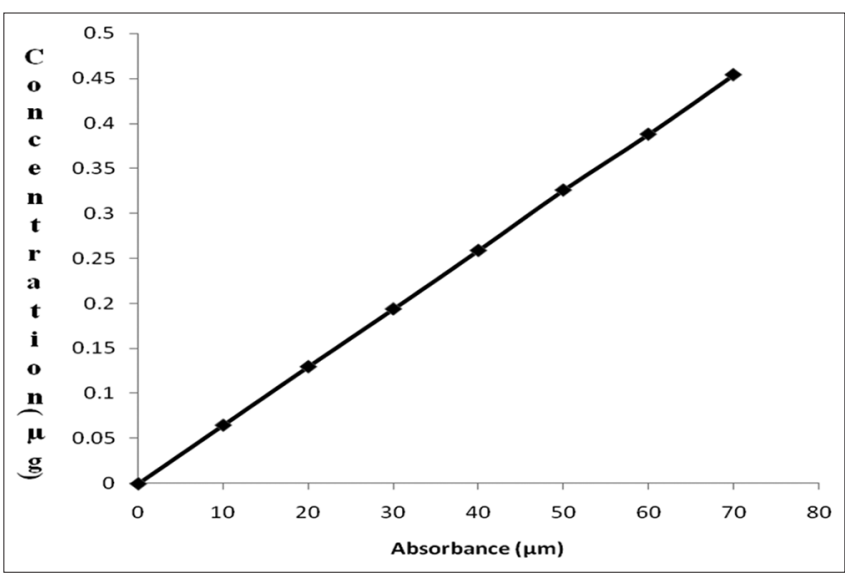

Fig. 1: Calibration curve of trazodone hydrochloride in $0.1 \mathrm{~N}$ hydrochloric acid

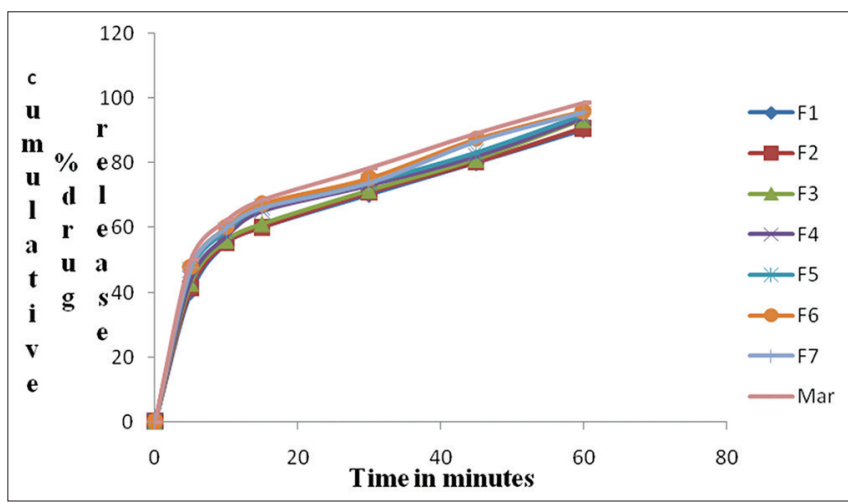

Fig. 2: In vitro drug release of trazodone hydrochloride from various tablet formulations

increased, in the case of FlowLac, the hardness of the tablets was enhanced. Friability values were found to be $<1 \%$ in all formulations and were found within the limits. The disintegration time of the tablet has to be optimized to develop fast disintegrating tablets. In all the formulations, the drug content was examined to be high ( $\geq 96.17 \%)$. Water absorption ratio, as well as the wetting time, is considered as an important criterion for understanding the capability of disintegrants to swell in the existence of a small quantity of water, and it was found to be in the range of $68.59-73.21 \%$ in $21-30$ s, respectively (Table 6), drug release studies were conducted with $0.1 \mathrm{~N}$ hydrochloric acid, and the dissolution profile is illustrated in Table 7 and Fig. 2; the in vitro drug release for formulation F6 showed the better release of drug when compared to the marketed product (Mar) as shown in Fig. 2.

\section{CONCLUSION}

In the present study, seven formulations have been formulated, of which F6 showed good results. The method of preparation of tablets was done by simple direct compression of the drug with excipients followed by single-stage compression which guarantees reproducible batches of tablets. The results showed the influence of physicochemical 
Table 6: Post-compression parameters for trazodone hydrochloride orodispersible tablets

\begin{tabular}{lllll}
\hline Batch no & Disintegration time (s) & Wetting time (s) & Assay (\%) & Water absorption ratio (\%) \\
\hline F1 & 58 & 30 & 96.56 & 72.51 \\
F2 & 59 & 28 & 96.45 & 71.63 \\
F3 & 25 & 97.43 & 69.79 \\
F4 & 27 & 96.34 & 70.58 \\
F5 & 59 & 24 & 96.24 & 71.31 \\
F6 & 58 & 21 & 98.12 & 68.59 \\
F7 & 55 & 23 & 96.45 & 73.21 \\
\hline
\end{tabular}

Table 7: Dissolution of trazodone hydrochloride in $0.1 \mathrm{~N}$ hydrochloric acid of $\mathrm{pH} 1.2$ from tablets of F1-F7 with the marketed product

\begin{tabular}{|c|c|c|c|c|c|c|c|c|}
\hline \multirow[t]{2}{*}{ Time (min) } & \multicolumn{8}{|c|}{$\%$ CDR } \\
\hline & F1 & F2 & F3 & F4 & F5 & F6 & F7 & Marketed product \\
\hline 00 & 0 & 0 & 0 & 0 & 0 & 0 & 0 & 0 \\
\hline 05 & 40.12 & 41.23 & 42.85 & 44.15 & 46.85 & 47.89 & 47.67 & 50.12 \\
\hline 10 & 55.26 & 55.39 & 56.13 & 57.55 & 59.15 & 60.27 & 60.12 & 62.25 \\
\hline 15 & 60.18 & 60.19 & 61.23 & 65.23 & 66.41 & 67.46 & 66.23 & 68.54 \\
\hline 30 & 70.29 & 70.89 & 71.56 & 73.28 & 74.16 & 75.45 & 74.01 & 78.45 \\
\hline 45 & 80.15 & 80.27 & 81.23 & 82.26 & 83.45 & 87.56 & 86.78 & 89.12 \\
\hline 60 & 90.27 & 90.89 & 93.56 & 94.12 & 95.13 & 96.17 & 95.78 & 98.56 \\
\hline
\end{tabular}

CDR: Cumulative drug release

parameters on the excipients used in tablet preparation. The precompression parameters comprising the angle of repose, bulk density, tapped density, compressibility index, and Hausner's ratio were evaluated and the drug powder showed good flow properties. In the drug profile the formulation F6 exhibited maximum drug release profile when compared to the innovated product as indicated in Table 7 and Fig. 2. Hence, the formulation F6 was contemplated as the top formulation and supplementary studies will be carried out for the profitable induction of the product.

\section{REFERENCES}

1. Behnke KSogaard JMartin SBauml JRavindran AVAgren HLachmann L, Liebermann AH. The Theory and Practice of Industrial Pharmacy. $3^{\text {rd }}$ ed. New York: Lippincott Williams and Wilkins Publisher; 1986.

2. Allen VL, Popovich NG, Ansel CH. Ansel's Pharmaceutical dosage form and drug delivery system $8^{\text {th }}$ ed. New York: Lippincott Williams and Wilkins Publisher; 2005.

3. Bentley AO. Ernest Alexander Rawlins. Bentley's Textbook of Pharmaceutics. $8^{\text {th }}$ ed. London: Bailliere Tindall Publisher; 1995.

4. Sastry SV, Nyashadam JR, Fix JA. Recent technological advances in oral drug delivery: A review. Pharm Sci Technolo Today 2000;3:138-45.

5. Fu Y, Yang S, Jeong SH, Kimura S, Park K. Orally fast disintegrating tablets: Developments, technologies, taste-masking and clinical studies. Crit Rev Ther Drug Carrier Syst 2004;21:433-76.

6. Seager H. Drug-delivery products and the zydis fast-dissolving dosage form. J Pharm Pharmacol 1998;50:375-82.

7. Habib W, Khankari R, Hontz J. Fast-dissolve drug delivery systems. Crit Rev Ther Drug Carrier Syst 2000;17:61-72.

8. Dobetti L. Fast disintegrating tablets. US Patent 2003;6:596,311.

9. Brown D. Orally disintegrating tablets taste over speed. Drug Del Tech
2003;3:58-61

10. Behnke K, Sogaard J, Martin S, Bauml J, Ravindran AV, Agren H, et al. Mirtazapine orally disintegrated tablet versus sertaline. A prospective onset of action study. J Clin Psychopharmacol 2003;23:358-64.

11. Jaccard TT, Leyder J. Une nouvelle forme galenique le lyoc. Ann Pharm Fr 1985;43:123-31

12. Dollo G, Chevanne F, Le Corre P, Chemtob C, Le Verge R. Bioavailability of phloroglucinol in man. J Pharm Belg 1999;54:75-82.

13. Gafițanu E, Dumistrăcel I, Antochi S. Formulations and bioavailability of propyphenazone in lyophilized tablets. Rev Med Chir Soc Med Nat Iasi 1991;95:127-8.

14. Clarke A, Brewer F. A new formulation of selegiline: Improved bioavailability and selectivity for MAO-B inhibition. J Neural Transm 2003; 110:124-5.

15. Dobetti L. Fast melting tablets: Developments and technologies. Pharm Technol Drug Deliv 2001;25 Supp1 9:44-50.

16. Meyers GL, Battist GE, Fuisz RC. Process and Apparatus for Making Rapidly Dissolving Dosage units and Products there Form. PCT Patent WC No. 95/34293-A1; 1995.

17. Allen LV, Wang B. Process for making a particulate support matrix for making a rapidly dissolving dosage forms. US Patent 2001;6:199-207.

18. Kuno Y, Kojima M, Ando S, Nakagami H. Evaluation of rapidly disintegrating tablets manufactured by phase transition of sugar alcohols. J Control Release 2005;105:16-22.

19. Yu DG, Shen XX, Han J, Zhu LM, Branford-White C, Li XY, et al. Oral Fast-Dissolving DDD Fabricated Using 3DP, Bioinformatics and Biomedical Engineering. The $2^{\text {nd }}$ International Conference; 2008. p. $1602-5$.

20. Gregory GK. Pharmaceutical Dosage form Packages. US patent 1981;4:305-502.

21. SchatzbergAF, NemeroffCB, editors. Textbook of Psychopharmacology. $4^{\text {th }}$ ed. Washington, DC: American Psychiatric Publisher; 2009. 